\title{
A ilustração que representa um assunto científico é também científica? Uma experiência de ensino.
}

\author{
Is the illustration representing a scientific subject is scientific also? A teaching \\ experience.
}

\author{
Tatiana de Trotta
}

ilustração científica, anatomia humana, ensino, estilo e sintaxe visual

\begin{abstract}
A motivação para o desenvolvimento deste artigo surgiu com as ponderações de iniciandas científicas sobre ilustrações de anatomia humana disponíveis na internet e em impressos físicos. Elas participaram do programa de iniciação científica da Universidade Tecnológica Federal do Paraná - UTFPR, cujo projeto versou sobre a informação em saúde e doença a partir de ilustrações sobre anatomia humana disponível para usuários em geral e/ou utilizadas com pacientes. Com a variedade de ilustrações em diferentes estilos que tratam sobre conteúdos científicos, surgiu a questão: sendo o assunto de cunho médico-científico as ilustrações poderiam ser igualmente compreendidas como científicas? Assim o objetivo deste artigo esteve em descrever minimamente o estilo visual científico para que seja um instrumento de diferenciação no momento de distingui-lo do não científico. A metodologia usada para isto foi o de análise descritiva de estilo, onde em nível sintático se observa sua construção visual. Assim foram estabelecidos parâmetros que classificam e diferenciam a ilustração científica das outras ilustrações. Isto auxiliou o entendimento e reconhecimento da ilustração científica pelas iniciandas, possibilitando um estudo adequado.
\end{abstract}

scientific illustration, human anatomy, teaching, style and visual syntax

The motivation for the development of this article arose with the ponderings of scientific initiations on illustrations of human anatomy available on the Internet and in physical forms. They participated in the scientific initiation program of the Federal Technological University - Paraná, whose project focused on information on health and disease from illustrations about human anatomy available to users in general and / or used with patients. With the variety of illustrations in different styles dealing with scientific content, the question arose: could the illustrations be scientifically understood as the medical-scientific subject? Thus the objective of this article was to describe minimally the scientific visual style so that it is an instrument of differentiation in the moment of distinguishing it from the non-scientific. The methodology used for this was that of descriptive analysis of style, where in syntactic level its visual construction is observed. Thus, parameters have been established that classify and differentiate scientific illustrations from other illustrations. This helped the understanding and recognition of the scientific illustration by the initiators, allowing an adequate study.

\section{Introdução}

O projeto intitulado: "A ilustração como informação sobre saúde" foi homologado no PDTI da UTFPR ${ }^{2}$, com dois anos de duração e fim em outubro de 2019. Ele teve a participação de três alunas de graduação ${ }^{3}$, onde cada uma desenvolveu atividades dentro do tema determinado em planos de trabalho. Todos os planos de trabalho do projeto tiveram como limitador a presença obrigatória de ilustrações de anatomia humana com conteúdo sobre saúde ou doença. As três orientadas participaram do projeto como voluntárias.

\footnotetext{
${ }_{1}^{1}$ Programa de Pesquisa e de Desenvolvimento Tecnológico e Inovação.

${ }^{2}$ Universidade Tecnológica Federal do Paraná.

${ }^{3}$ Tecnologia em Design Gráfico e Bacharelado em Design, cursos oferecidos pelo Departamento Acadêmico de Desenho Industrial - DADIN.
}

Anais do 9 CIDI e 9 CONGIC

Luciane Maria Fadel, Carla Spinillo, Anderson Horta,

Cristina Portugal (orgs.)

Sociedade Brasileira de Design da Informação - SBDI

Belo Horizonte | Brasil | 2019

ISBN 978-85-212-1728-2
Proceedings of the 9th CIDI and 9th CONGIC

Luciane Maria Fadel, Carla Spinillo, Anderson Horta,

Cristina Portugal (orgs.)

Sociedade Brasileira de Design da Informação - SBDI

Belo Horizonte | Brazil | 2019

ISBN 978-85-212-1728-2 
Os primeiros retornos das alunas na orientação foram sobre o reconhecimento da ilustração científica, ou seja, como saber o que faz com que algumas ilustrações sejam científicas e outras não? Ou ainda, se a ilustração trata de ciência ela não seria também científica?

A orientação incluiu encontros semanais com desenvolvimento de relatos escritos, conversas e esclarecimentos, além de sugestões de leitura de textos específicos no escopo do projeto e orientação sobre o desenvolvimento para pesquisas visuais e em base de dados.

Entre os assuntos estudados foi necessário elucidar como diferenciar a ilustração do tipo científico de outros tipos de ilustrações. Apesar de se poder mostrar seu aspecto formal, percebeu-se necessário apontar atributos e aspectos essenciais para seu reconhecimento.

Na representação de estado de saúde ou doença são frequentemente usadas imagens anatômicas, muitas vezes estas imagens são desenhos e ilustrações. Para estudar ilustrações que carregam informação de valor científico é necessário saber quando ela é científica, ou seja, ilustração científica. Arrisca-se dizer que mesmo uma ilustração não científica, em alguns casos, pode esclarecer a ciência, mas para ser chamada de científica ela tem que atender a condições essenciais.

llustração científica é, por definição, um desenho preciso. Seu objetivo é mostrar a quem a estuda a mesma imagem que quem a desenvolveu tinha quando olhou para o assunto. A ilustração científica deve informar de forma tão completa e precisa sobre o assunto que representa a ponto daquele que a estuda se tornar consciente e esclarecido, como se ele mesmo o tivesse visto (Wood, 1994).

A ilustração científica da anatomia humana é um dos vários tipos de ilustração científica existentes. Ela está contida no escopo de estudos médicos que a utiliza para documentar, estudar e investigar a medicina. "A habilidade em representar a anatomia humana se mostrou uma prerrogativa para estudo e avanços no exercício da medicina” (Kickhöfel, 2011).

Compreender as diferenças que classificam as ilustrações serem de um tipo ou de outros tipos se torna importante inclusive para interpretar os desenhos que carregam informações sobre saúde ou doença.

\section{Tipos e estilos de ilustrações sobre saúde}

Por vários séculos as ilustrações científicas estiveram afastadas das pessoas em geral, sendo mais comumente inteligíveis para artistas e cientistas que as produziam e estudavam (Kemp, 2010). Estas ilustrações científicas (Figura 1) eram de grande precisão e detalhamento com o intuito de estudar o corpo humano, entender o funcionamento do organismo e descrevê-lo com exatidão

Figura 1: llustração científica do corpo humano de Antonio Serantoni (Mascagni, 1833).

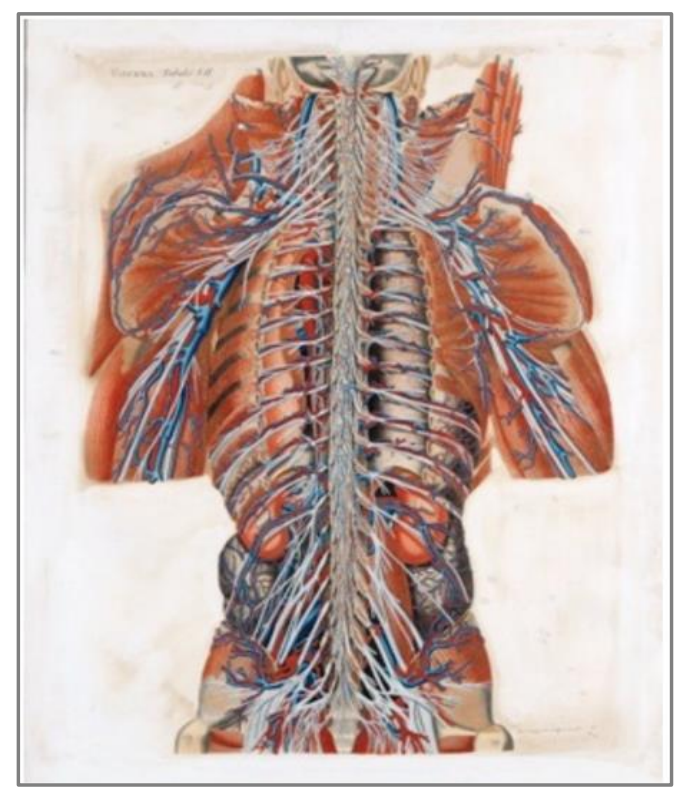


Atualmente, por causa de dados disponíveis principalmente na internet, faz com que a informação se torne cada vez mais acessível do que em tempos anteriores. Pode-se encontrar com certa facilidade imagens do corpo humano, explicativas sobre estado de saúde ou de doença, disponíveis ao público em geral.

Contudo, a ilustração científica possui o mesmo preceito em que, intenciona apresentar estruturas em aparência e organização, de forma que sejam similares ao referente ${ }^{4}$ e assim se tornem compreensíveis entre aqueles que as assistem, para que sejam documentos que possam ensinar, informar, descrever e comunicar (Silva, 2009).

A ilustração sobre anatomia humana hoje encontrada, que interessa a este artigo, usada para o entendimento do corpo humano pode versar sobre:

1. Prevenção de doenças.

2. Sintomas de enfermidades.

3. Transmissão/Evolução de doenças.

4. Atuação de medicamentos.

5. Funcionamento do corpo humano.

Entretanto, estes temas podem se apresentar em diferentes tipos de ilustração (narrativa, editorial, técnica, científica) e qualquer um deles pode exibir diferentes estilos. Estilo é um conjunto de características sintáticas que pode ser observado na aparência geral da ilustração. Segundo Sousa (2013) é possível identificar três estilos básicos e recorrentes, cujas variações e hibridismos possibilitaram toda a diversidade conhecida: "visual-naturalista", "racionalistasimbólico" e "emocional-expressivo".

O naturalista é mais recorrente na pintura acadêmica e na fotografia. [...] As representações pictóricas [...] assemelham-se ao modo como os seres humanos percebem as coisas ao seu redor. Por isso, a linguagem pictórica promove representações muito verossímeis, assemelhando-se com as imagens compostas pela observação direta das coisas do mundo (Sousa, 2013, sem p.).

O estilo da ilustração científica é normalmente chamado de naturalista, pois trata dos assuntos da ciência com representações verossímeis. Segundo Sousa (2013, sem p.)

[...] são dois os elementos básicos de expressão: a linha e a mancha; os quais definem dois modos básicos de representação: o pictórico-naturalista e o gráfico-idealista. [...] [No] uso de linhas e de manchas, é possível a expressão ou a representação de cinco aspectos ou valores das formas visíveis, que são: cores, tonalidades, texturas, volumes e configurações. [...] Em decorrência da organização dessas formas, ainda, é possível a representação das figuras naturais ou ideais ou a composição de arranjos visuais abstratos. Tudo isso compõe a sintaxe visual, com base na

apresentação ou na organização da matéria visual por elementos compositores de formas e de figuras expressivo-representativas.

O estilo da ilustração científica da anatomia humana é chamado de "realista convencionado" (Trotta, 2017, p. 157). Porque, em anatomia humana se faz uma representação do que seriam os tecidos orgânicos naturalmente, ou seja, sem intervenções de qualquer natureza (p.ex. cirúrgica) em vida ou de aparência do corpo fixado em formol (CFF) em morte, por causa disso existe uma idealização da realidade. Ideia em acordo com a possibilidade de representações de estilo por meio da sintaxe visual de "figuras naturais ou ideais" (Sousa, 2013, sem p.).

Como diferentes estilos podem ser encontrados para abordar temas sobre saúde ou doença de cunho científico, percebeu-se a necessidade em distinguir minimamente as ilustrações, de maneira que se possam aferir as que são científicas. Isto se deu pela necessidade de instruir as alunas no desenvolvimento dos planos de trabalho no referido projeto.

Sendo assim, surgiu a ideia de construir uma tabela sintática de estilo que, por meio de análise visual, quantifica em diferentes graus as características essenciais para reconhecer a ilustração científica sobre anatomia humana.

É necessário ao menos citar que muitas vezes infográficos ${ }^{5}$ são utilizados para informar ao público em geral sobre questões de saúde e eles podem conter em sua narrativa ilustrações de anatomia humana. Assim como animações que são utilizadas para simular ou demonstrar

\footnotetext{
${ }^{4}$ Referente é o objeto ou fenômeno do mundo real.

${ }^{5}$ Infográfico é a combinação de imagens e textos. Nele também se elencam aspectos característicos, como: relação interdependente entre os textos e as imagens; disposição de elementos informacionais em camadas; possibilidade de uma estrutura de leitura não-linear (Miranda \& Andrade, 2017, p. 376).
} 
funcionamento de sistemas biológicos e também podem ser usadas para representar estruturas anatômicas.

Hoje, os esboços dos séculos passados deram lugar à elaboração de animações por computador que estão ajudando os pesquisadores a entender o funcionamento interno de algumas das ciências mais misteriosas e minúsculas que existem - a dos processos celulares dentro de nossos corpos. As animações não são criadas apenas para mostrar o que funciona, mas também para ajudar os cientistas a entender melhor por que suas hipóteses podem não funcionar (Owens-Liston, 2013).

De qualquer forma, infográficos e animações, mesmo que apresentem anatomia de modo simplificado, normalmente presentes nestas situações poderiam ser analisados com a aplicação da Tabela, pois estes casos estão por ela previstos. Contudo, neste artigo não se analisa narrativa de nenhuma natureza e sim ilustrações anatômicas pontuais no conteúdo imagético dos sites observados.

\section{Instrumento de aferição}

A metodologia usada para reconhecer as ilustrações foi o de análise visual, análise esta realizada em observação ao aspecto das ilustrações selecionadas. Para tanto, foi desenhada uma Tabela Sintática para aferição do estilo ilustrativo científico, inspirada no Modelo descritivo de sintaxe visual sobre anatomia humana (Trotta, 2017, p.170) e no contexto ilustrativo quanto aos momentos executivos da ilustração científica da anatomia humana (Trotta, 2017, p. 168). Foi necessário considerar alguns elementos sintáticos do momento 'anterior' ao desenvolvimento da ilustração científica da anatomia humana (presentes em configuração), pois o referido Modelo contempla somente a sintaxe do momento 'durante' o desenvolvimento daquelas ilustrações.

Aquele Modelo possui três categorias sintáticas: Forma, Volume e Superfície. Os elementos, desdobramentos e especificações das categorias sintáticas Forma e Volume, não foram incluídos na tabela porque suas unidades sintáticas são pertinentes para quem vai desenvolver a ilustração científica (objetivo do Modelo), como neste artigo se analisa ilustrações já existentes a aferição daquelas unidades não se fez necessária. Já na categoria sintática Superfície, o desdobramento foi incluído por apresentar resultado visual pertinente à análise.

Quadro 1: Tabela sintática para aferição do estilo ilustrativo científico. Legenda: $\mathrm{A}=$ alto grau, $\mathrm{M}=$ médio grau, $\mathrm{B}=$ baixo grau.

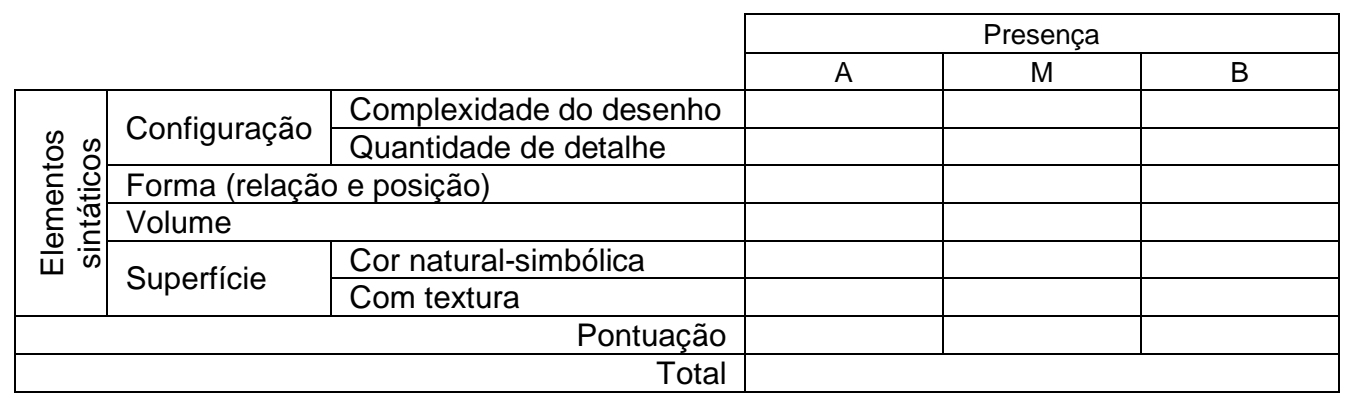

Vale salientar que, o Quadro 1 foi criado para aferir somente o estilo específico do tipo de ilustração nomeada científica. A intenção é marcar os espaços destinados á Presença, na Tabela Sintática de Estilo (Quadro 1), escolhendo os aspectos sintáticos elencados no lado esquerdo da tabela como: alto $(A)$, médio $(M)$ ou baixo $(B)$ grau, ou seja, abundante (alto), regular (médio) ou escasso (baixo).

\section{4 llustrações selecionadas}

Foram selecionadas ilustrações independentes do modo como foram produzidas, poderiam ser: digitalizada, vetorial ou bitmap. Deveriam conter algum dos assuntos estipulados (saúde ou 
doença) e deveriam estar disponíveis de forma aberta e irrestrita na internet, portanto dirigidas para o público geral.

As ilustrações foram escolhidas por conveniência para o desenvolvimento deste artigo. Determinou-se usar duas ilustrações de cada tema enumerado no Item 2 deste artigo, com aparência variada para demonstrar o funcionamento da Tabela Sintática de Estilo (Quadro 1).

Vale lembrar que, as páginas consultadas poderiam até possuir mais de uma ilustração, além da presença de outros tipos de imagens (p.ex. fotografia). Contudo, para efeito deste artigo foi analisada apenas a ilustração que explica sobre o assunto ou notícia abordada no site e que se enquadra nos temas já definidos.

Tanto neste artigo como nos planos de trabalho, os parâmetros para seleção de ilustrações tiveram a obrigatoriedade de serem com origem institucional ou de representante da área de saúde responsável por seu conteúdo. É preciso salientar que, mesmo assim, não se analisa o teor científico das ilustrações e da mídia em que veiculam, as análises são das ilustrações em si.

O Quadro 2 apresenta ilustrações sobre prevenção de doenças. O conjunto de ilustrações e texto da esquerda explica como ocorre a digestão e exibe alimentos que contribuem e dificultam a evacuação. O conjunto de ilustrações e texto da direita mostra estudo que comprova a influência da flora intestinal na resposta imunológica a algumas vacinas.

Quadro 2: Prevenção de doenças.

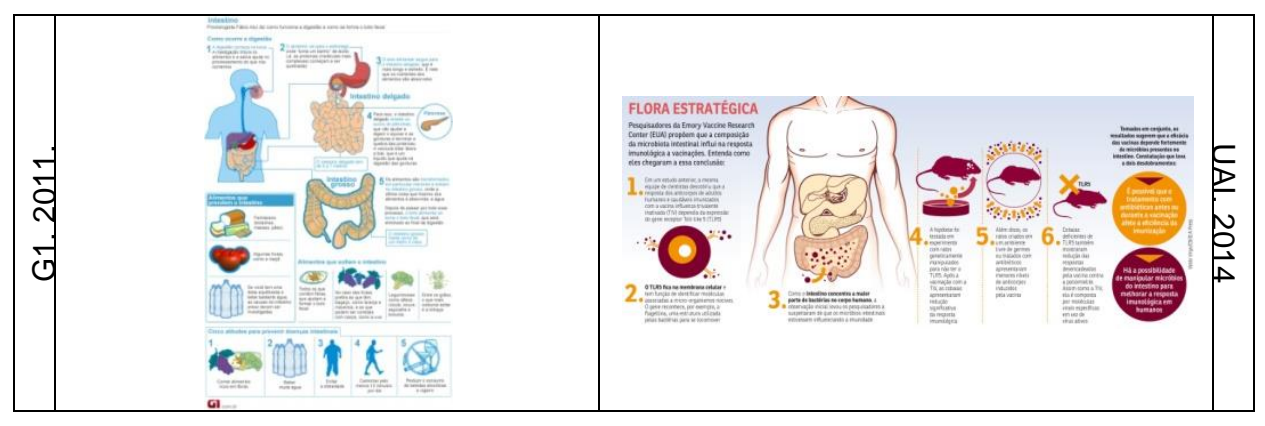

O Quadro 3 possui ilustrações que representam sintomas sobre doenças respiratórias. Elas apresentam o resultado visual do muco nasal causado pela Rinite alérgica (esquerda) e pela Sinusite (direita).

Quadro 3: Sintomas de enfermidades.

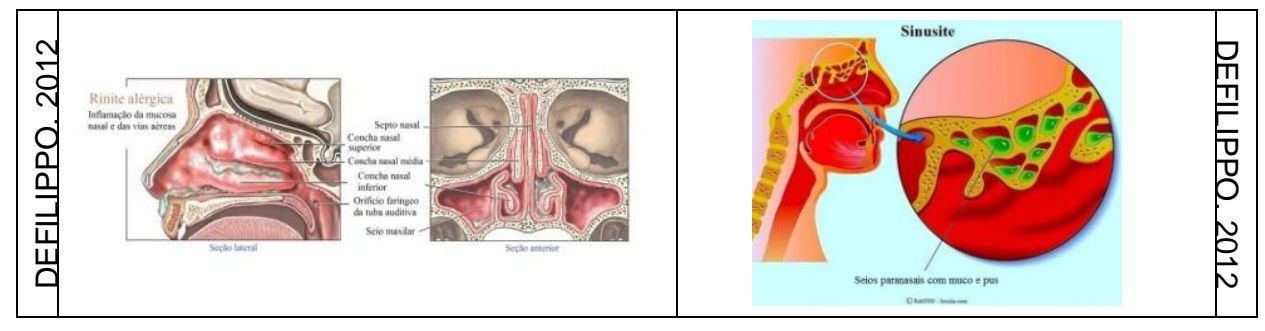

A ilustração da esquerda no Quadro 4 mostra o desenvolvimento do parasita da malária no corpo humano e sua transmissão. Já a ilustração da direita mostra a evolução da Hepatite B. 
Quadro 4: Transmissão/Evolução de doenças.

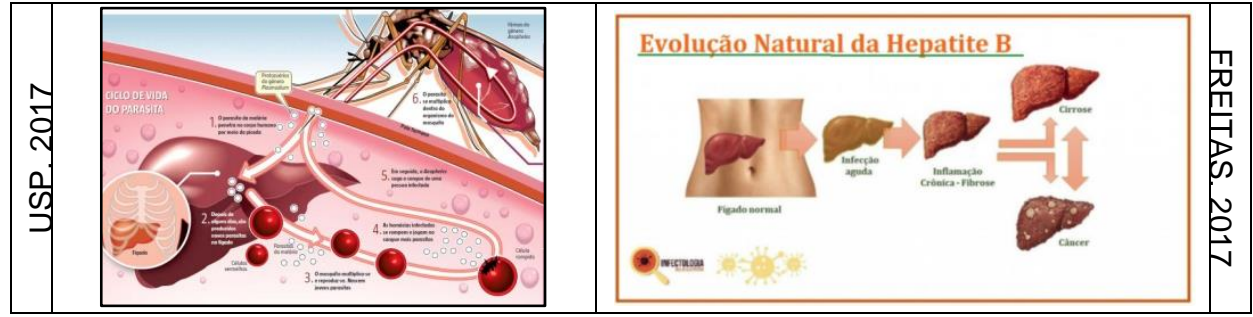

O Quadro 5 possui ilustrações que apresentam a atuação de medicamentos no corpo humano. À esquerda sobre descongestionante nasal e à direita sobre uso de bombinha por asmáticos, apresentando a diferença entre a via respiratória de uma pessoa saudável e outra com asma.

Quadro 5: Atuação de medicamentos.

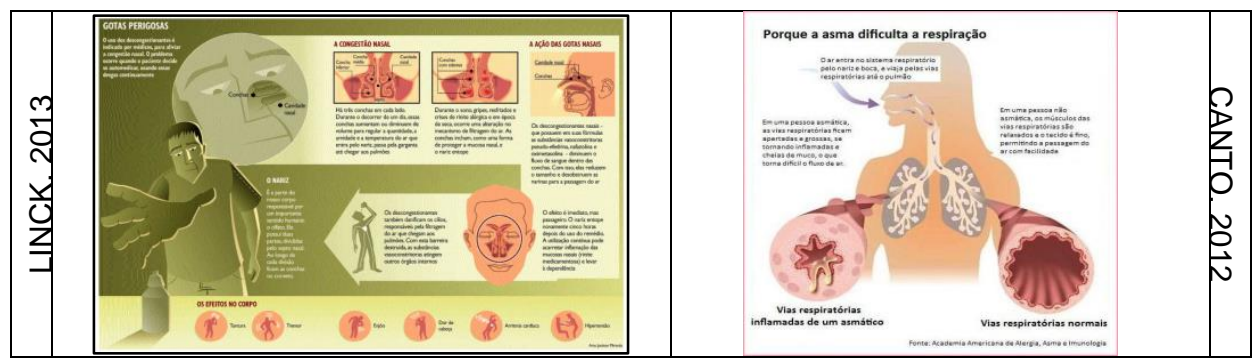

As duas ilustrações no Quadro 6 mostram e rotulam os órgãos que fazem parte do sistema digestório do corpo humano.

Quadro 6: Funcionamento do corpo humano

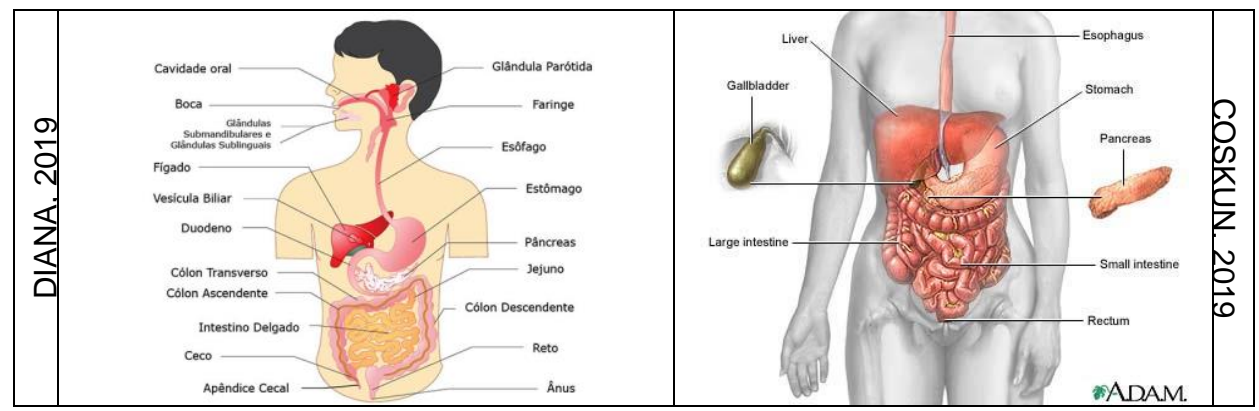

\section{Análise e Resultado}

Para analisar as ilustrações, é preciso considerar que a ilustração científica deve apresentar a aparência das estruturas anatômicas muito próximas da realidade. Assim, quanto mais alto o grau de presença das categorias e elementos sintáticos, mais próxima está a ilustração de poder ser considerada do tipo científico.

Para dimensionar, ser parecido com o referente, é necessário conhecer a anatomia humana. As ilustrações de Dr. Netter (Figura 2) podem ser usadas como parâmetro, visto que ele é reconhecido como o mestre mais importante da ilustração médica e seus desenhos anatômicos são o padrão pelo qual todos os outros da arte médica são medidos e julgados (Elsevier, 2013).

Para mensurar a análise foi estipulada pontuação para a presença de itens marcados em cada coluna: 3 pontos para cada item na coluna A, 2 pontos para cada item na coluna $\mathrm{M}$ e 1 ponto para cada item na coluna B. Ao final da tabela é feita a soma por coluna e depois é 
calculado o total para a ilustração. Quando a pontuação for igual ou superior a 16 pontos 0 resultado da análise considera que a ilustração estudada é científica.

Os 16 pontos para nomear a ilustração como do tipo científico foi estipulado da seguinte maneira: pelo menos em cada uma das categorias sintáticas os elementos devem possuir alto grau de presença (=12 pontos), nos elementos restantes é necessário possuir ao menos médio grau de presença ( $=4$ pontos) totalizando 16 pontos. A pontuação vale mesmo que na análise os pontos se distribuam de outra maneira. Uma vez que ela pode apresentar algum elemento com pontuação 1 e equilibre com outro elemento com pontuação 3 . Esta ressalva é feita, pois é sabido que na ilustração científica da anatomia humana "quanto mais se privilegia o volume menos possível se torna o trabalho de texturização e vice-versa" (Trotta, 2017, p. 160).

Figura 2: Coração - ilustração de Dr. Netter (Elsevier, 2013).

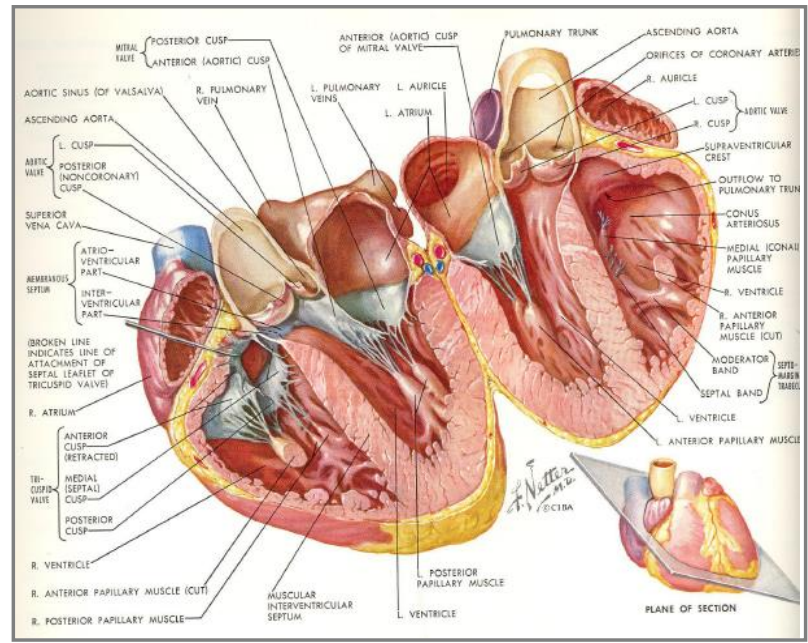

$\mathrm{Na}$ Tabela 1, as ilustrações não podem ser consideradas científicas porque possuem poucos elementos sintáticos com alto grau de presença. Mesmo que os órgãos estejam na posição, relações de proporção e formatos corretos, a configuração, o volume e a superfície não apresentam estruturas suficientemente parecidas com as naturais.

Tabela 1: Prevenção de doenças

\begin{tabular}{|c|c|c|c|c|c|c|c|c|}
\hline \\
\hline & & & & & & & & \\
\hline & & & A & M & $\mathrm{B}$ & A & M & $B$ \\
\hline \multirow{6}{*}{ 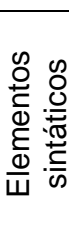 } & \multirow{2}{*}{ Configuração } & Complexidade do desenho & & $x$ & & & $x$ & \\
\hline & & Quantidade de detalhe & & $\mathrm{x}$ & & & $x$ & \\
\hline & \multicolumn{2}{|c|}{ Forma - relação e posição } & $\mathrm{x}$ & & & $\mathrm{x}$ & & \\
\hline & \multicolumn{2}{|l|}{ Volume } & & & $x$ & & & $\mathrm{x}$ \\
\hline & \multirow{2}{*}{ Superfície } & Cor natural-simbólica & & & $\mathrm{x}$ & & $\mathrm{x}$ & \\
\hline & & Com textura & & & $\mathrm{x}$ & & $x$ & \\
\hline \multicolumn{3}{|r|}{ Pontuação } & 3 & 4 & 3 & 3 & 8 & 1 \\
\hline & & Total & \multicolumn{3}{|c|}{10} & \multicolumn{3}{|c|}{12} \\
\hline
\end{tabular}

$\mathrm{Na}$ Tabela 2, as ilustrações possuem uma aparência bem mais próxima das naturais. Porém, apenas a da esquerda pode ser intitulada como científica. A ilustração da direita tem duas categorias sintáticas inteiras em médio grau de presença impossibilitando chamá-la de científica. 
Tabela 2: Sintomas de enfermidades.

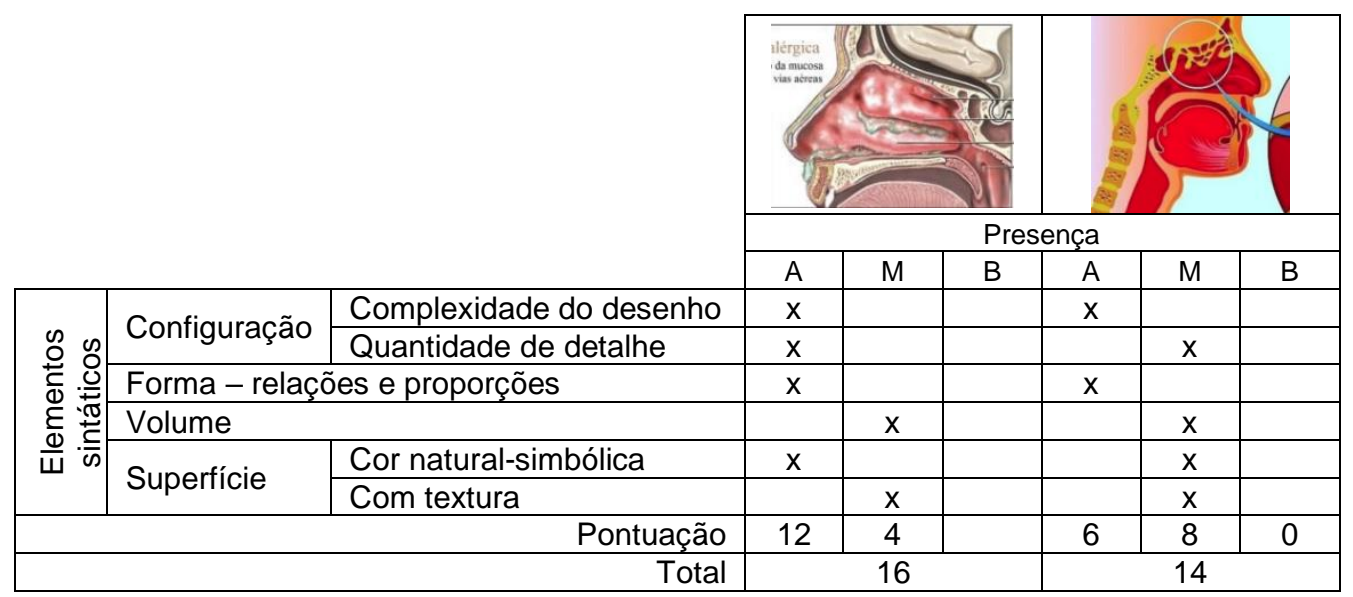

$\mathrm{Na}$ Tabela 3, as ilustrações apresentarem o órgão de estudo em destaque com representação em forma, volume e superfície próxima às naturais. Entretanto, a da esquerda não possui configuração e forma iguais ao natural, o que a descaracteriza como científica. Já a da direita possui muitos elementos em alto grau de presença o que faz dela científica

Tabela 3: Transmissão/Evolução de doenças.

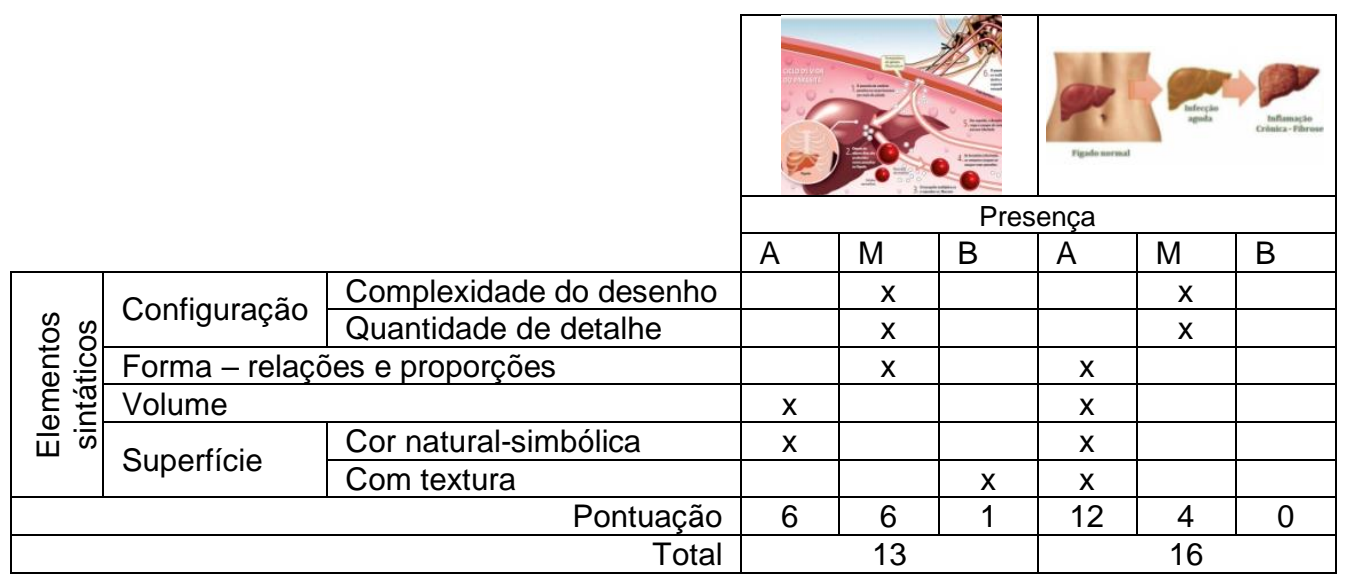

$\mathrm{Na}$ Tabela 4, as ilustrações estão no limiar da pontuação. Isso pode criar confusões quando observadas fora da Tabela, mas com sua aplicação e observação sistemática de cada um dos elementos elencados, pode-se fazê-lo com maior segurança. Pois, são exatamente estes os casos mais geram dúvidas. Elas não são consideradas científicas por não possuírem os graus mínimos de presença dos elementos sintáticos. É certo que mesmo nas ilustrações científicas existem simplificações, indefinição volumétrica ou de superfície e até omissões de estruturas adjacentes, mas isto foi considerado na pontuação mínima e as situações a pouco mencionadas não costumam acontecer simultaneamente em ilustrações quando científicas. 
Tabela 4: Atuação de medicamentos.

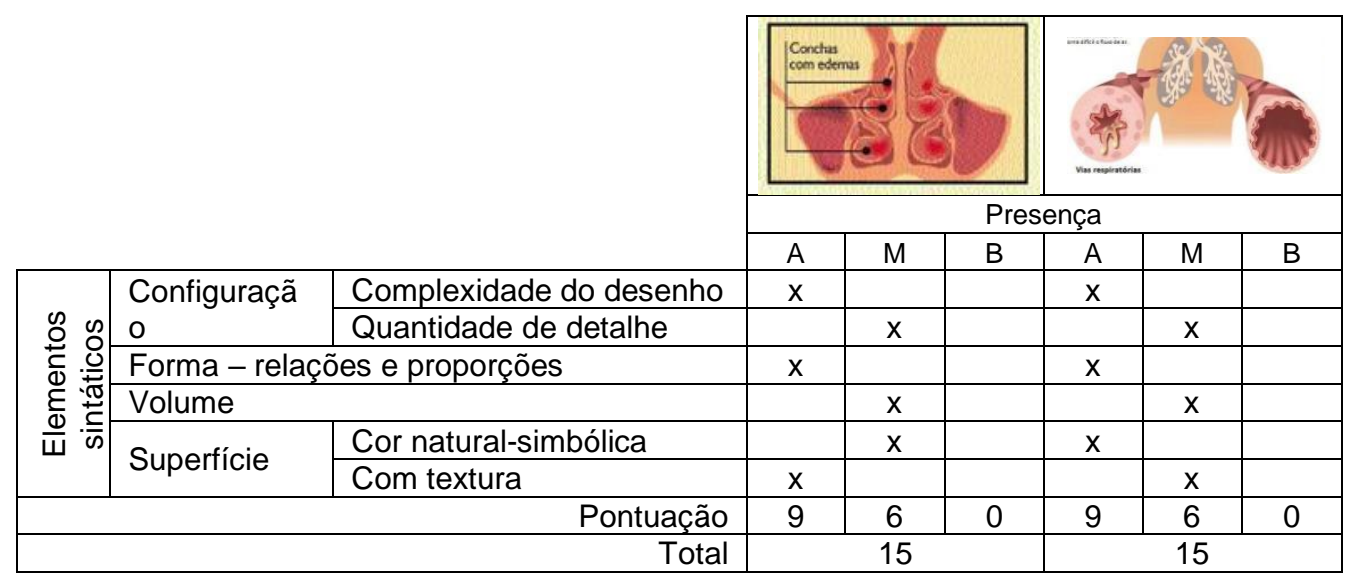

$\mathrm{Na}$ Tabela 5, as ilustrações intencionam mostrar o sistema digestório humano. A ilustração da esquerda não possui nenhum dos elementos sintáticos em alto grau de presença. Já a ilustração da direita possui todos os elementos em alto grau de presença, o que faz dessa última uma ilustração científica.

Tabela 5: Funcionamento do corpo humano.

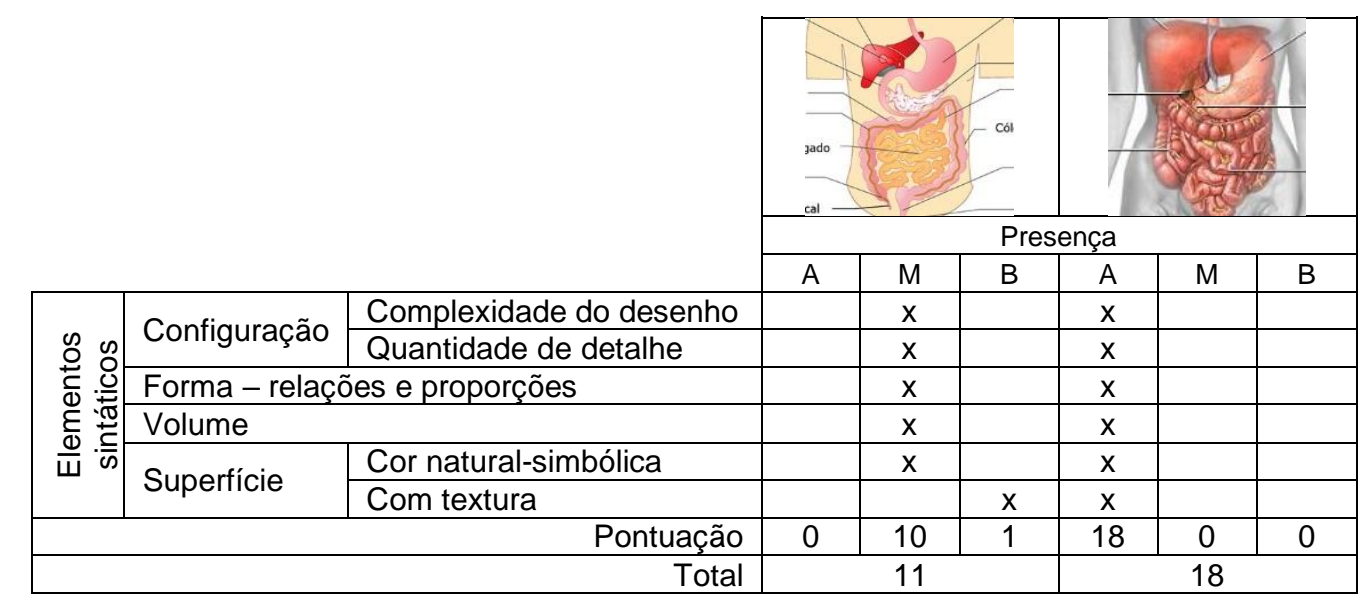

A análise mostrou que as diferentes maneiras de ilustrar os estados de saúde e de doença nem sempre apresentam ilustrações científicas. Das 10 ilustrações analisadas 3 podem ser chamadas de científicas pela pontuação alcançada na Tabela sintática para aferição do estilo ilustrativo científico.

A Figura 2 exibe as ilustrações organizadas conforme pontuação alcançada na aferição com o uso da referida Tabela. Elas estão distribuídas da maior (acima) para a menor (abaixo) pontuação, ou seja, científicas (acima da linha pontilhada) para não científicas. 
Figura 2: Distribuição das ilustrações conforme pontuação alcançada por meio da sintaxe visual da análise.

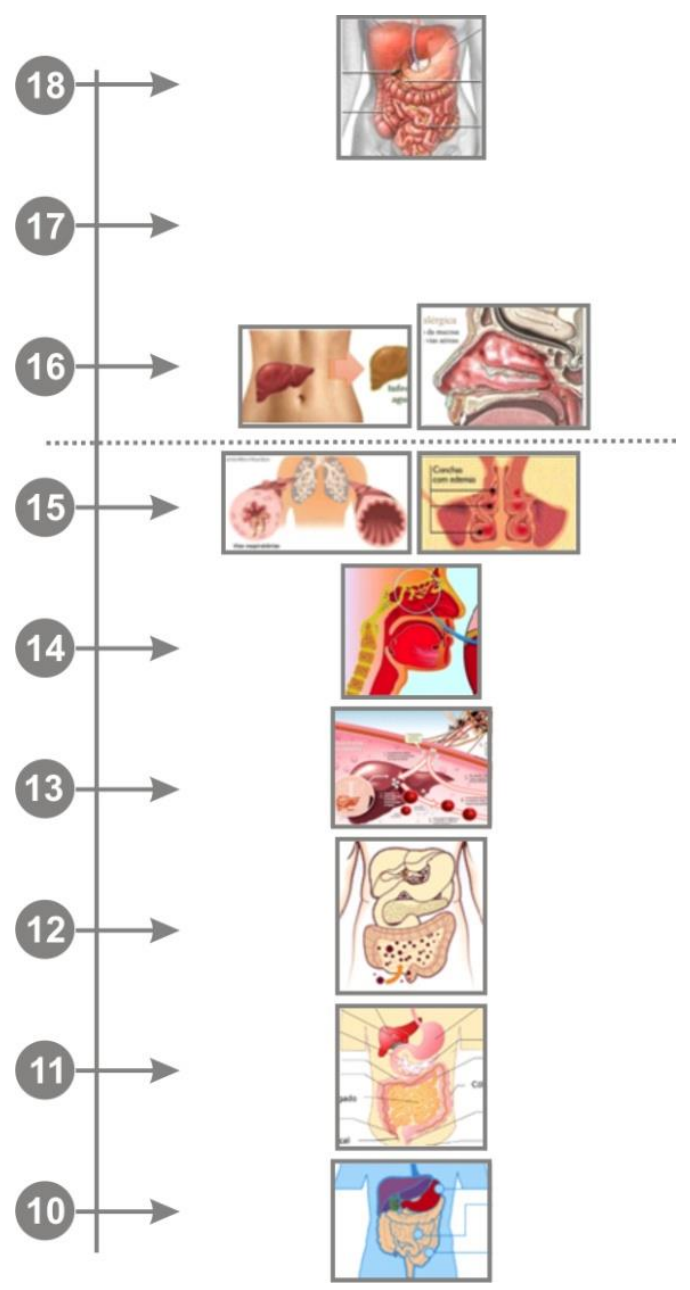

Vale lembrar que, como as ilustrações focam em uma mensagem para um público geral elas consideram este destino. Talvez por esta razão, várias vezes se observe que alguma parte da ilustração é simplificada formal, volumétrica ou superficialmente. Normalmente isto acontece nas regiões onde tema central da mensagem não se está presente (caso das ilustrações que atingiram 15 e 14 pontos).

Contudo, isto não desmerece o conteúdo, a intenção da mensagem e nem mesmo a própria ilustração. Entretanto, não pode ser nomeada de ilustração científica. Desse modo, é possível afirmar que quando as ilustrações atingem 16 ou mais pontos se está diante de uma informação visual coerente com o estilo real convencionado atribuído às ilustrações científicas sobre anatomia humana.

O cuidado que se deve tomar é que quanto menor for a pontuação em relação ao grau de presença de elementos sintáticos nas ilustrações, maior é a chance de ela apresentar alguma informação visual que prejudique a compreensão correta das estruturas anatômicas ou da intenção da mensagem original.

\section{Conclusão}

Não se pretendeu criar regras inflexíveis, mas demonstrar a importância de se ter definições mensuráveis para poder classificar de forma mínima tipos de ilustrações, aqui, especificamente a ilustração científica sobre anatomia humana. Isto auxiliou seu entendimento e reconhecimento, possibilitando um estudo adequado. Saber destacar a ilustração científica de outros tipos, como também dispor de suas características pode ser útil inclusive para tomadas de decisão no desenvolvimento de um projeto de design. Sua distinção no escopo das ilustrações facilitou a visibilidade de seus atributos formais e o ensino deste assunto. 
Por intermédio da aplicação da referida Tabela, foi possível elencar os aspectos sintáticos de análise que minimamente estabelecem a condição para observar de forma resumida a condição de uma ilustração ser nomeada científica.

Este é um estudo sobre análise visual de ilustrações por meio da Tabela sintática para aferição de estilo científico que foi desenvolvido por uma demanda específica advindo das orientações para iniciação científica. A Tabela cumpriu seu papel em atingir de forma efetiva a compreensão das alunas no entendimento do que é ser visualmente científica. A análise por meio da Tabela proporcionou confiança e autonomia para escolhas e seleção de ilustrações para o estudo delineado nos planos de trabalho.

A resposta para a pergunta: $A$ ilustração que representa um assunto científico é também científica? É não. A ilustração que representa um assunto científico quando dirigida para o público em geral, na maioria das vezes, não é científica. Então a afirmação do item 1, onde se arriscou dizer que uma ilustração não científica pode esclarecer a ciência, sim ela pode, desde que o rigor científico necessário seja preservado.

Para que a aferição da Tabela seja conclusiva é necessário fazer um maior número de análises. Uma oportunidade de pesquisa é a continuação deste estudo pela averiguação do entendimento do conteúdo visual dos sites que tratam sobre questões de saúde e doença pelos usuários. Como pesquisa futura, verificar se pode ser adaptada para outros estilos.

\section{Referências}

Canto, E. (2012). Como atua a bombinha para asmáticos? Redes moderna. Acesso em: 17 setembro 2018. URL: <http://redes.moderna.com.br/2012/12/13/como-atua-abombinha-para-asmaticos/>

Coskun, R. Digestive System. Functions of the Human Body Systems. Acesso: 08 julho 2019. URL: <https://sites.google.com/site/functionsofthehumanbodysystems/digestivesystem>.

Defilippo, M. (2012). Dr. Muco no nariz - verde, branco, amarelo e com sangue. Fisioterapia para todos. Acesso em. 08 julho 2019. URL: <https://www.fisioterapiaparatodos.com/p/sintomas/muco-no-nariz/>.

Diana, J. B. (2019). Sistema Digestivo, Sistema Digestório. Biologia -Anatomia e fisiologia humanas. Toda Matéria [site]. Acesso: 08 julho 2019. URL: https://www.todamateria.com.br/sistema-digestivo-sistema-digestorio/.

Elsevier. Netter, F. H. Acesso em: julho 2013. URL: https://www.netterimages.com/artist-frankh-netter.html.

Freitas, K. (2017). Fases da Infecção pela Hepatite B. Hepatite B: O Que Você Precisa Saber. Acesso: 08 julho 2019. URL: https://www.drakeillafreitas.com.br/hepatite-b-o-que-voceprecisa-saber/.

G1 - Grupo Globo. (2011). Comer fibras, beber água e fazer exercícios ajudam a soltar o intestino. Bem Estar. Acesso em: 07 julho 2019. URL:

http://g1.globo.com/bemestar/noticia/2011/10/comer-fibras-e-beber-agua-ajudam-soltaro-intestino-destacam-medicos.html.

Kemp, M. (2010). Style and non-style in anatomical illustration: From Renaissance Humanism to Henry. Journal of Anatomy. N 216, pp. 192-208. Acesso em: 16 maio 2013. URL: http://onlinelibrary.wiley.com/doi/10.1111/j.1469-7580.2009.01181.x/full.

Hodges, E. R. S. (2003). The guild handbook of scientific illustration. New Jersey: John Wiley \& Sons.

Linck, V. (2013). A verdade sobre os descongestionantes. Tem ciência no teu chá! [blog] Acesso em: 17 setembro 2018. URL: https://temciencianoteucha.com/2013/10/10/averdade-sobre-os-descongestionantes-nasais/.

Mascagni, P. (1833). Anatomia Universa: Tavola V. [ilustração Antonio Serantoni]. Banca dati di Immagini per la Didattica. Acesso em : 31 maio 2013. URL: http://www.indire.it/cgi- 
bin/diafindcgi4?dbnpath=/isis3/dati/dia/immag\&query=D-

JFVG3H3G\&formato=Completo\&unico=1\&file_header=/archivi/dia/header.php.

Miranda F.; Andrade R, C. (2017). Pensar Infográfico: uma proposta de ensino introdutório de infografia sob a perspectiva da linguagem gráfica. Revista Infodesign [online]. São Paulo. Vol.14 ( 3).

Owens-Liston, P. (2013). Can scientific animations lead to new discoveries? Janet iwasa, ph.d., says next-generation visualization speeds research. Algor1thms for innovation. $U$ Health - University of Utah. Acesso em: 08 jun 2019. URL:

https://uofuhealth.utah.edu/innovation/blog/2013/07/scientific-animations.php.

Silva, E. R. B. (2009). Divulgação científica: Imagens facilitam a compreensão da ciência. Ciência e Cultura. São Paulo. Vol. 61 (3), pp. 64-5. Acesso em: julho 2012. URL: http://cienciaecultura.bvs.brpdfcicv61n3a23v61n3.pdf.

Sousa, R. P. L. (2010). Gramática Comparada da Representação Gráfica. Convergências: Revista de investigação e ensino das artes. Instituto Politécnico de Castelo. Vol.III (6). Acesso em: agosto 2013. URL: http://convergencias.esart.ipcb.pt/artigo/92.

Trotta, T. de. (2017). Modelo descritivo de sintaxe visual para ilustração científica do corpo humano. Tese (Doutorado). UFPR: Curitiba.

UAI - O grande portal dos mineiros. (2013). Remédio trata o diabetes e ajuda a emagrecer. Saúde plena. Acesso em: 07 julho 2019. URL:

http://sites.uai.com.br/app/noticia/saudeplena/noticias/2013/10/31/noticia_saudeplena, 1 46218/remedio-trata-o-diabetes-e-ajuda-a-emagrecer.shtml.

UAI - O grande portal dos mineiros. (2014). Bactérias intestinais interferem em vacinas. Saúde Plena. Acesso em: 08 julho 2019. URL:

http://sites.uai.com.br/app/noticia/saudeplena/noticias/2014/09/20/noticia_saudeplena,1 50336/bacterias-intestinais-interferem-em-vacinas.shtml.

USP - Universidade de São Paulo. (2016). Pesquisas desvendam regulação do desenvolvimento do parasita da malária. Jornal da USP. Acesso em: novembro 2017. URL: https://jornal.usp.br/ciencias/ciencias-biologicas/pesquisas-desvendamregulacao-do-desenvolvimento-do-parasita-da-malaria/.

Wood, Phyllis, AMI, GNSI. (1994). Scientific Illustration: a guide to biological, zoological, and medical rendering techniques, design, printing, and display. New York: John Wiley \$ Sons.

\section{Sobre a autora}

Tatiana de Trotta, Doutora, Professora Titular, UTFPR, Brasil, <trotta@utfpr.edu.br> 